\title{
Preparation and Antiflame Performance of Expandable Graphite Modified with Sodium Hexametaphosphate
}

\author{
Hongmei Zhao, ${ }^{1,2}$ Xiuyan Pang, ${ }^{1}$ and Zhixiao Zhai ${ }^{1}$ \\ ${ }^{1}$ College of Chemistry and Environmental Science, Key Laboratory of Analytical Science and Technology of Hebei Province, \\ Hebei University, Baoding 071002, China \\ ${ }^{2}$ Department of VIP, Affiliated Hospital of Hebei University, Baoding, Hebei 071000, China
}

Correspondence should be addressed to Xiuyan Pang; pxy833@163.com

Received 12 May 2015; Accepted 9 July 2015

Academic Editor: Iliya Rashkov

Copyright (C) 2015 Hongmei Zhao et al. This is an open access article distributed under the Creative Commons Attribution License, which permits unrestricted use, distribution, and reproduction in any medium, provided the original work is properly cited.

\begin{abstract}
A kind of polyphosphate modified expandable graphite $\left(\mathrm{EG}_{p}\right)$ was prepared in graphite oxidation and intercalation reaction with $\mathrm{KMnO}_{4}$ as oxidant, $\mathrm{H}_{2} \mathrm{SO}_{4}$ as intercalator, and sodium hexametaphosphate (SHMP) as assistant intercalator. The feasible mass ratio of $\mathrm{C}: \mathrm{KMnO}_{4}: \mathrm{H}_{2} \mathrm{SO}_{4}$ (98\%): SHMP was determined as $1.0: 0.3: 4.5: 0.6, \mathrm{H}_{2} \mathrm{SO}_{4}$ was diluted to 77 wt $\%$ before intercalation reaction, and the reaction lasted for $40 \mathrm{~min}$ at $40^{\circ} \mathrm{C}$. Expanded volume and initial expansion temperature of the prepared $\mathrm{EG}_{p}$ reached $600 \mathrm{~mL} / \mathrm{g}\left(\right.$ at $800^{\circ} \mathrm{C}$ ) and $151^{\circ} \mathrm{C}$, respectively. X-ray diffraction spectroscopy testified the intercalation and layer structure of $\mathrm{EG}_{p}$, and Fourier transform infrared spectroscopy illuminated the intercalated functional groups. Flame retardance of the prepared $\mathrm{EG}_{p}$ and the referenced EG (with only $\mathrm{H}_{2} \mathrm{SO}_{4}$ as intercalator) for linear low density polyethylene (LLDPE) was also investigated. Addition of $30 \mathrm{wt} \% \mathrm{EG}_{p}$ to the polymer improved the limiting oxygen index (LOI) from 17.5 to $27.3 \%$. On the other hand, the LOI of the same amount of the referenced EG was only $24.6 \%$. Assistant intercalation of SHMP improved the dilatability and flame retardancy.
\end{abstract}

\section{Introduction}

Graphite is a kind of crystal compound with layer structure, and its intercalating compound named expandable graphite can be prepared when noncarbonaceous reactants are inserted into graphite layers through chemical or electrochemical reaction $[1,2]$. Expandable graphite has many good properties: it can be used as catalyst in the synthesis of organic ester [3], and when it expands at high temperature, a poriferous material called expanded graphite is prepared. Expanded graphite is a kind of effective adsorbent for heavy oil and dyes wastewater [4-6]. At the same time, expandable graphite is a good intumescent type flame-retardant for its good capability of halogen-free and nondropping [7, 8]. When expandable graphite exposes to flame, it can give a swollen multicellular char, which can protect materials from heat and oxygen. Simultaneously, expandable graphite absorbs huge heat during the instant expansion, which can decrease the burning temperature. When it is oxidized on reaction with $\mathrm{H}_{2} \mathrm{SO}_{4}$ at high temperature, the released $\mathrm{CO}_{2}$, $\mathrm{SO}_{2}$, and $\mathrm{H}_{2} \mathrm{O}$ can reduce concentration of combustible gas [9]. All these characteristics indicate expandable graphite is a good flame retardant.

When expandable graphite is used as flame retardant, its dilatability (shown as expanded volume (EV)) and thermal stability (shown as initial expansion temperature $T_{0}$ ) are very important parameters [10], and it can be divided into three kinds: low $T_{0}$ (between 80 and $150^{\circ} \mathrm{C}$ ), middle $T_{0}$ (between 180 and $240^{\circ} \mathrm{C}$ ), and high $T_{0}$ (between 250 and $300^{\circ} \mathrm{C}$ ) expandable graphite.

In the preparation of expandable graphite, reactants and theirs contents, such as oxidant, intercalator and assistant intercalator, and reaction temperature, reaction time can all affect its dilatability. With $\mathrm{KMnO}_{4}$ as oxidant and $\mathrm{H}_{2} \mathrm{SO}_{4}$ and acetic acid as intercalator and assistant intercalator, expandable graphite with a $T_{0}$ of $160^{\circ} \mathrm{C}$ and EV of $460 \mathrm{~mL} \mathrm{~g}^{-1}$ was prepared [11]. Expandable graphite holding a $T_{0}$ of $310^{\circ} \mathrm{C}$ and $\mathrm{EV}$ of $270 \mathrm{~mL} \mathrm{~g}^{-1}$ could be prepared with $85 \mathrm{wt} \% \mathrm{H}_{2} \mathrm{SO}_{4}$ 
as intercalator, $\mathrm{KMnO}_{4}$ as oxidant, and $\mathrm{FeSO}_{4}$ as close agent [12].

Linear low-density polyethylene (LLDPE) possesses low machining temperature (less than $140^{\circ} \mathrm{C}$ ) and it is very flammable. In this research, with $\mathrm{KMnO}_{4}$ as oxidant and $\mathrm{H}_{2} \mathrm{SO}_{4}$ as intercalator, and sodium hexametaphosphate (SHMP) as assistant intercalator, the phosphate modified expandable graphite $\left(\mathrm{EG}_{p}\right)$ with high dilatability and fitting for LLDPE flame retardancy was prepared. The dosages of $\mathrm{KMnO}_{4}, \mathrm{H}_{2} \mathrm{SO}_{4}$, and SHMP and reaction temperature and reaction time were optimized in graphite intercalating reaction. X-ray diffraction spectroscopy (XRD) and Fourier transform infrared spectroscopy (FTIR) were employed to illuminate the layer structure and intercalating components. Flame retardancy, indicated as limiting oxygen index (LOI) of the $\mathrm{EG}_{p}$ for LLDPE, was also investigated.

\section{Experimental}

2.1. Materials and Reagents. Natural flake graphite with an average flake size of $0.3 \mathrm{~mm}$ and a carbon content of $92 \%$ was provided by Action Carbon Co. Ltd., Baoding, China. Analytical reagent of SHMP was obtained from Fuchen, Tianjin, China. $\mathrm{H}_{2} \mathrm{SO}_{4}(98 \%)$ and $\mathrm{KMnO}_{4}$ are all analytical agents. LLDPE (7042, $0.918 \mathrm{~g} / \mathrm{cm}^{3}$, melt index $\left.2.0 \mathrm{~g} / 10 \mathrm{~min}\right)$.

\subsection{Experimental Method}

2.2.1. $\mathrm{EG}_{p}$ Preparing Procedure and Its Optimization. In the intercalating reaction of material graphite, the reactants were quantified according to a definite mass ratio of $\mathrm{C}: \mathrm{H}_{2} \mathrm{SO}_{4}$ (98\%) : $\mathrm{KMnO}_{4}$ : $\mathrm{SHMP}$, and $\mathrm{H}_{2} \mathrm{SO}_{4}$ was diluted with deionized water before reaction. Then, the quantified reactants were mixed and stirred in the order of the diluted $\mathrm{H}_{2} \mathrm{SO}_{4}$, SHMP, C, and $\mathrm{KMnO}_{4}$ in a $250 \mathrm{~mL}$ beaker, controlled at a constant temperature. After reaction, the solid phase was washed with deionized water and dipped in water for $2.0 \mathrm{~h}$ until $\mathrm{pH}$ of the wastewater reached 6.0-7.0, and then $\mathrm{EG}_{p}$ is obtained after filtration and drying at $50-60^{\circ} \mathrm{C}$ for about $5.0 \mathrm{~h}$. Its dilatability showing as $\mathrm{EV}$ and $T_{0}$ was detected according to the reported method [11].

The influences of mass ratio of graphite to $\mathrm{KMnO}_{4}$, SHMP, and $\mathrm{H}_{2} \mathrm{SO}_{4}$ and its concentration, reaction time, and temperature on $\mathrm{EG}_{p}$ dilatability were tested as follows.

2.2.2. Influence of $\mathrm{KMnO}_{4}$ Dosage on $\mathrm{EG}_{p}$ Dilatability. In order to investigate the influence of $\mathrm{KMnO}_{4}$ dosage on dilatability, single-factor experiments were carried out by changing $\mathrm{KMnO}_{4}$ dosage in the range of $0.2 \sim 0.6 \mathrm{~g} / \mathrm{g}$. According to the method mentioned above, experiments were carried out under the constant mass ratio C:SHMP: $\mathrm{H}_{2} \mathrm{SO}_{4}$ (98\%) of $1.0: 0.6: 4.5$. Before reaction, $\mathrm{H}_{2} \mathrm{SO}_{4}$ was diluted to $80 \mathrm{wt} \%$, and the reaction lasted for $1.0 \mathrm{~h}$ at $40^{\circ} \mathrm{C}$.

Figure 1 shows the changes of EV with the amount of $\mathrm{KMnO}_{4}$. As an oxidant, insufficient $\mathrm{KMnO}_{4}$ will cause incomplete oxygenation of graphite and decrease of $\mathrm{EV}$, while superfluous $\mathrm{KMnO}_{4}$ will cause excessive oxygenation of graphite, which leads to a decrease in EG granularity and

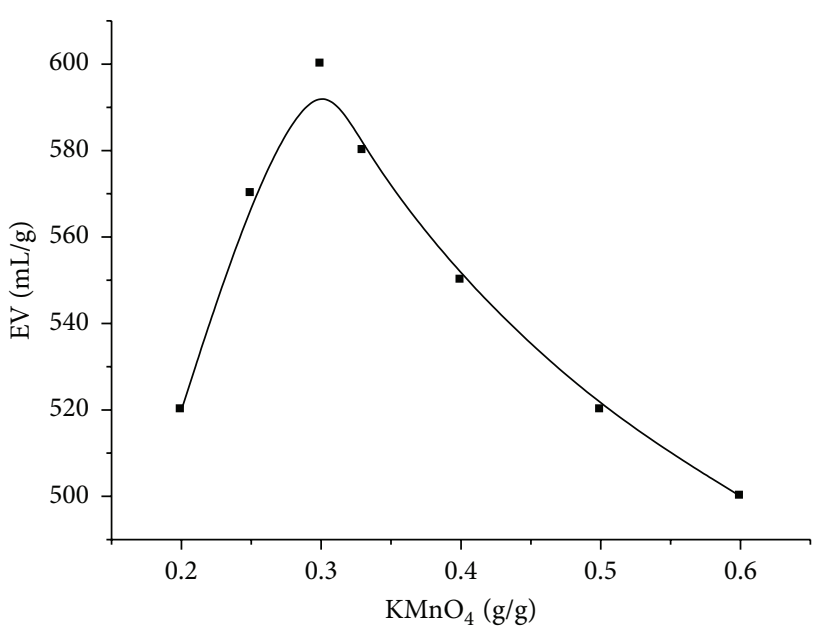

FIgURE 1: Influence of $\mathrm{KMnO}_{4}$ dosage on EV.

$\mathrm{EV}$. When the mass ratio of $\mathrm{KMnO}_{4}$ to $\mathrm{C}$ is controlled as $0.3 \mathrm{~g} / \mathrm{g}$, the prepared EG possesses a higher EV of $600 \mathrm{~mL} / \mathrm{g}$, and then the feasible dosage of $\mathrm{KMnO}_{4}$ can be set as $0.3 \mathrm{~g} / \mathrm{g}$.

2.2.3. Influence of $\mathrm{H}_{2} \mathrm{SO}_{4}$ Dosage on EG Dilatability. In order to investigate its influence and feasible dosage, $\mathrm{H}_{2} \mathrm{SO}_{4}$ dosage was changed in the range of 3.5 6.0 g/g. Experiments were carried out under the constant mass ratio C: $\mathrm{SHMP}: \mathrm{KMnO}_{4}$ of $1.0: 0.6: 0.3$, the reaction lasted for $1 \mathrm{~h}$ at $40^{\circ} \mathrm{C}$, and $\mathrm{H}_{2} \mathrm{SO}_{4}$ was diluted to $80 \mathrm{wt} \%$.

Figure 2 shows the changes of $\mathrm{EV}$ with $\mathrm{H}_{2} \mathrm{SO}_{4}$ amount. In intercalation reaction of graphite, $\mathrm{H}_{2} \mathrm{SO}_{4}$ acts as intercalator and oxidant and provides an acidic environment for the oxidability of $\mathrm{KMnO}_{4}$. Equation (1) shows that insufficient $\mathrm{H}_{2} \mathrm{SO}_{4}$ will incur a poor oxidation of $\mathrm{KMnO}_{4}$ and $\mathrm{H}_{2} \mathrm{SO}_{4}$, cause an incomplete intercalation reaction, and lead to the decrease of dilatability. With the increase of $\mathrm{H}_{2} \mathrm{SO}_{4}$ dosage, the oxidation of $\mathrm{KMnO}_{4}$ and $\mathrm{H}_{2} \mathrm{SO}_{4}$ is enhanced, causing the intercalation reaction gradually completed and leading to the increases of dilatability. When the $\mathrm{H}_{2} \mathrm{SO}_{4}$ dosage achieves a balance in three areas, the prepared $\mathrm{EG}$ will present high $\mathrm{EV}$. Conversely, $\mathrm{EV}$ will decrease when the $\mathrm{H}_{2} \mathrm{SO}_{4}$ dosage is under or over the suitable value. Results shown in Figure 2 present that the feasible mass ratio of $\mathrm{H}_{2} \mathrm{SO}_{4}$ to $\mathrm{C}$ is $4.5 \mathrm{~g} / \mathrm{g}$ :

$$
\begin{aligned}
E_{\mathrm{MnO}_{4}{ }^{-} / \mathrm{Mn}^{2+}}= & E_{\mathrm{MnO}_{4}{ }^{-} / \mathrm{Mn}^{2+}}^{\circ} \\
& +\left(\frac{0.05916}{5}\right) \log \left\{\frac{\left[\mathrm{H}^{+}\right]^{8}\left[\mathrm{MnO}_{4}{ }^{-}\right]}{\left[\mathrm{Mn}^{2+}\right]}\right\} .
\end{aligned}
$$

2.2.4. Influence of $\mathrm{H}_{2} \mathrm{SO}_{4}$ Concentration on EG Dilatability. Under the constant mass ratio C:SHMP: $\mathrm{KMnO}_{4}: \mathrm{H}_{2} \mathrm{SO}_{4}$ $(98 \%)$ of $1.0: 0.6: 0.3: 4.5(\mathrm{~g} / \mathrm{g})$, the reaction lasted for $1 \mathrm{~h}$ at $40^{\circ} \mathrm{C}$, and influence of $\mathrm{H}_{2} \mathrm{SO}_{4} \mathrm{wt} \%$ in the reaction was detected and shown in Figure 3. Before reaction, $98 \mathrm{wt} \%$ $\mathrm{H}_{2} \mathrm{SO}_{4}$ was diluted with deionized water to different wt $\%$ in the range of $65 \% \sim 85 \%$.

Electrode potential of $\mathrm{MnO}_{4}{ }^{-} / \mathrm{Mn}^{2+}$ can be calculated according to (1). It shows that there is a positive correlation 


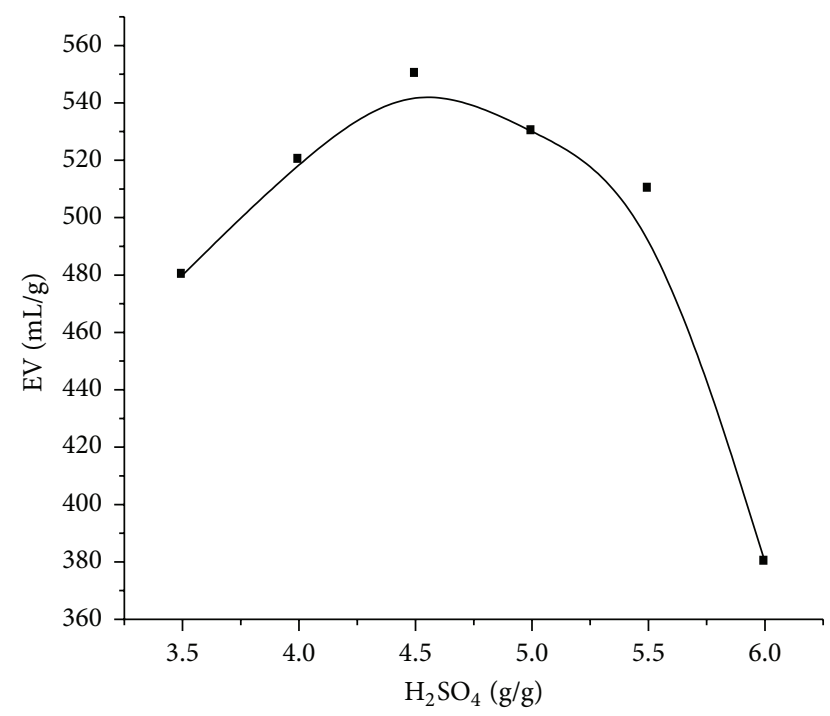

Figure 2: Influence of $\mathrm{H}_{2} \mathrm{SO}_{4}$ dosage on EV.

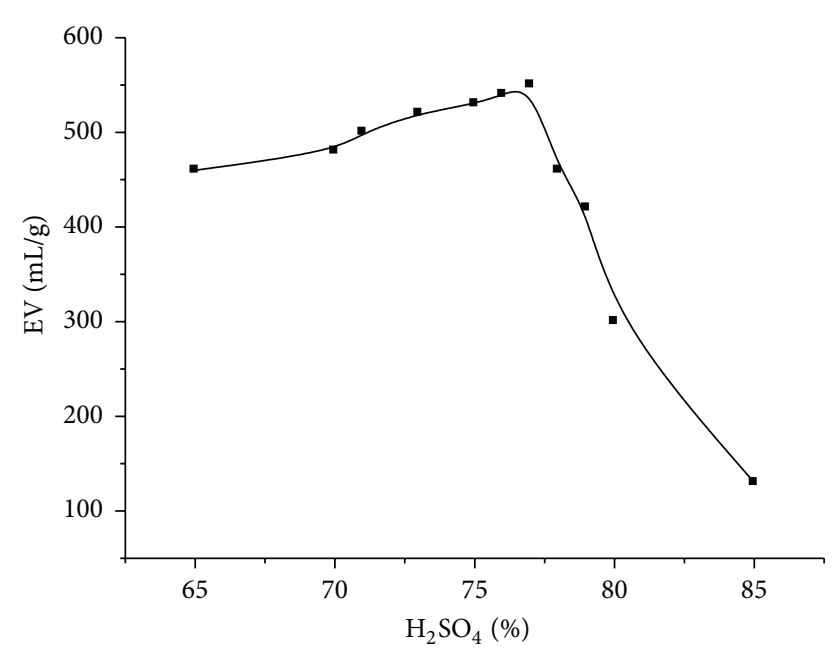

FIgURE 3: Influence of $\mathrm{H}_{2} \mathrm{SO}_{4}$ wt $\%$ on EV.

between $\left[\mathrm{H}^{+}\right]$and the oxidation of $\mathrm{KMnO}_{4}$. Therefore, within a certain range, the oxidation of $\mathrm{KMnO}_{4}$ is enhanced with the increase of $\mathrm{H}_{2} \mathrm{SO}_{4}$ concentration, causing the intercalation reaction gradually completed and leading to the increases of dilatability. But, with the further increase of $\mathrm{H}_{2} \mathrm{SO}_{4}$ concentration, it will cause the excessive oxidation of graphite when it is over a suitable concentration. As shown in experiment results, the feasible $\mathrm{H}_{2} \mathrm{SO}_{4}$ concentration is $77 \mathrm{wt} \%$.

2.2.5. Influence of $S H M P$ Dosage on EG Dilatability. Under the constant mass ratio $\mathrm{C}: \mathrm{H}_{2} \mathrm{SO}_{4}(98 \%): \mathrm{KMnO}_{4}$ of $1.0: 4.5: 0.3(\mathrm{~g} / \mathrm{g})$, the reaction lasted for $1 \mathrm{~h}$ at $40^{\circ} \mathrm{C}$ and $\mathrm{H}_{2} \mathrm{SO}_{4}$ was diluted to $77 \mathrm{wt} \%$, and the influence of SHMP dosage was detected in the range of $0.4 \sim 0.8 \mathrm{~g} / \mathrm{g}$.

As an assistant intercalator, increase of SHMP dosage can improve EG dilatability as shown in Figure 4 . When the mass ratio of SHMP : C is controlled as $0.6 \mathrm{~g} / \mathrm{g}$, EG holds a maximum of EV. Superfluous SHMP will cause the relative scarcity of $\mathrm{KMnO}_{4}$ and incomplete oxygenation of graphite.

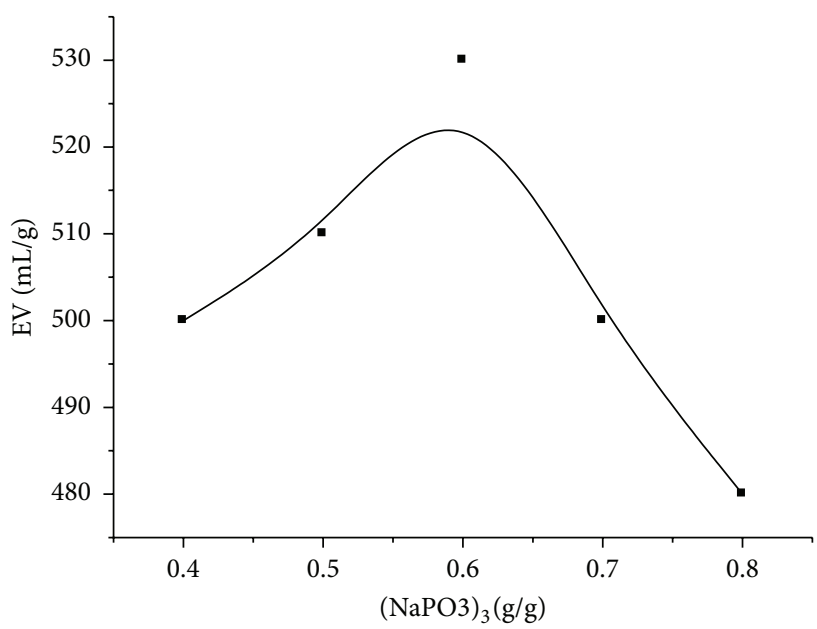

Figure 4: Influence of SHMP dosage on EV.

2.2.6. Influence of Reaction Temperature on EG Dilatability. Influence of reaction temperature on the reaction is mainly reflected in two aspects: reaction rate and balance direction. For the reaction rate, it is positively correlated with reaction temperature. Instead, for exothermic reaction, such as oxidization and intercalation of graphite, the degree of reverse reaction will increase greatly with the increase temperature. So reaction temperature creates different effects on the reaction rate and direction.

Under the constant mass ratio $\mathrm{C}: \mathrm{H}_{2} \mathrm{SO}_{4}$ (98\%): $\mathrm{KMnO}_{4}: \mathrm{SHMP}$ of $1.0: 4.5: 0.3: 0.6(\mathrm{~g} / \mathrm{g}), \mathrm{H}_{2} \mathrm{SO}_{4}$ diluted to $77 \mathrm{wt} \%$ before reaction, and reaction that lasted for $1 \mathrm{~h}$, the influence of reaction temperature on $\mathrm{EV}$ was detected. When it is less than $40^{\circ} \mathrm{C}$, the increase of temperature can improve EG dilatability. However, too high temperature causes the exothermic reaction releasing more heat and excessive oxygenation of graphite. So the feasible reaction temperature can be set as $40^{\circ} \mathrm{C}$.

2.2.7. Influence of Reaction Time on EG Dilatability. Under the constant mass ratio $\mathrm{C}: \mathrm{H}_{2} \mathrm{SO}_{4}(98 \%): \mathrm{KMnO}_{4}: \mathrm{SHMP}$ of $1.0: 4.5: 0.3: 0.6(\mathrm{~g} / \mathrm{g}), \mathrm{H}_{2} \mathrm{SO}_{4}$ diluted to $77 \mathrm{wt} \%$, and reaction temperature controlled at $40^{\circ} \mathrm{C}$, the influence of reaction time on EV was studied. Results show that extension of reaction time increases EG dilatability in the former $40 \mathrm{~min}$, and then it remains the same. Therefore, reaction time can be set as $40 \mathrm{~min}$.

\subsection{Characterization of the Samples}

2.3.1. XRD Analysis. XRD analysis for material graphite and the prepared expandable graphite were performed with a Y4Q X-ray diffractometer (Dandong, China) employing Nifiltered $\mathrm{Cu} \mathrm{K} \alpha$ radiation with $2 \theta$ ranging from $15^{\circ}$ to $70^{\circ}$.

2.3.2. FTIR Analysis. The prepared intercalating products were triturated and mixed with potassium bromide at the mass ratio of about $1: 100$. The powder was pressed into flake in mold, and FTIR spectra were recorded between 4000 and 
$400 \mathrm{~cm}^{-1}$ using FTS-40 FTIR spectrograph (America) with a resolution of $2 \mathrm{~cm}^{-1}$.

2.3.3. Sample Processing and LOI Detection. Mixtures of flame retardant and LLDPE were melted at $140^{\circ} \mathrm{C}$ in Muller (Jiangsu, China) and pressed at $10 \mathrm{MPa}$, and then samples were chopped into slivers with size of $120.0 \times 6.0 \times$ $3.0 \mathrm{~mm}^{3}$. The slivers were used to measure LOI according to GB/T2406-1993 with oxygen index instrument (Chengde, China).

\section{Results and Discussion}

3.1. Feasible Condition of $\mathrm{EG}_{p}$ Preparation. According to the experiment results, feasible conditions of $\mathrm{EG}_{p}$ preparation can be set as mass ratio C: $\mathrm{KMnO}_{4}: \mathrm{H}_{2} \mathrm{SO}_{4}(98 \%)$ : SHMP of $1.0: 0.3: 4.5: 0.6 ; \mathrm{H}_{2} \mathrm{SO}_{4}$ diluted to $77 \mathrm{wt} \%$ before reaction; intercalation reaction that lasted for $40 \mathrm{~min}$ at $40^{\circ} \mathrm{C}$. The EV of $E_{p}$ under different expansion temperature was detected, and it shows an increasing trend along with the increasing expansion temperature before $800^{\circ} \mathrm{C}$, and then it presents a decreasing trend caused by excessive oxygenation of $\mathrm{EG}_{p} . T_{0}$ and the maximum of $\mathrm{EV}$ are $151^{\circ} \mathrm{C}$ and $600 \mathrm{~mL} / \mathrm{g}$, respectively.

3.2. Preparation of the Referenced Expandable Graphite (EG). Compared with $\mathrm{EG}_{p}$, the referenced $\mathrm{EG}$ was prepared under the mass ratio $\mathrm{C}: \mathrm{KMnO}_{4}: \mathrm{H}_{2} \mathrm{SO}_{4}(98 \%)$ of $1.0: 0.3: 4.5$, and other conditions were the same as $\mathrm{EG}_{p} . T_{0}$ and the maximum of EV were detected as $205^{\circ} \mathrm{C}$ and $480 \mathrm{~mL} / \mathrm{g}$, respectively. SHMP obviously affects dilatability of $\mathrm{EG}_{p}$ and, what is more, addition of $0.6 \mathrm{~g} / \mathrm{g}$ SHMP in graphite intercalating reaction makes $\mathrm{EV}$ increase $25 \%$. $\mathrm{EG}_{p}$ will show better flame retardancy than EG for its good dilatability.

\subsection{Characterization of Graphite and \\ Its Intercalating Compounds}

3.3.1. XRD Analysis of Natural Graphite and $\mathrm{EG}_{p}$. XRD analyses for natural graphite and $\mathrm{EG}_{p}$ were performed. As shown in Figure 5 of natural graphite the two peaks with the interplanar crystal spacing of $3.34 \AA$ and $1.67 \AA$ corresponding to diffraction angles of $26.6^{\circ}$ and $54.8^{\circ}$ are the characteristic spectrum of natural graphite. As shown in Figure 5 of $\mathrm{EG}_{p}$ the peaks of $26.2^{\circ}$ and $55.4^{\circ}$ show that $\mathrm{EG}_{p}$ keeps the same layer structure as natural graphite. But it is worthy to note that the diffraction peak of $26.6^{\circ}$ transfers to smaller angle of about $26.2^{\circ}$. At the same time, it corresponds to a big interplanar crystal spacing of $3.44 \AA$ due to intercalation in graphene planes. It can be clearly seen that under the oxidation of $\mathrm{KMnO}_{4}$, the noncarbonaceous reactant can be easily inserted into the graphene planes, leading to the increase of interplanar crystal spacing.

3.3.2. FTIR Analysis of the Prepared Samples. Figure 6 shows FTIR spectra of the prepared $\mathrm{EG}_{p}$ and EG. As can be seen from the results, two samples both show the characteristic absorption peaks of $-\mathrm{OH}$ at 3430 , caused by intercalation of $\mathrm{H}_{2} \mathrm{SO}_{4}$ or $\mathrm{HSO}_{4}^{-}$. At the same time, the peak at $1630 \mathrm{~cm}^{-1}$

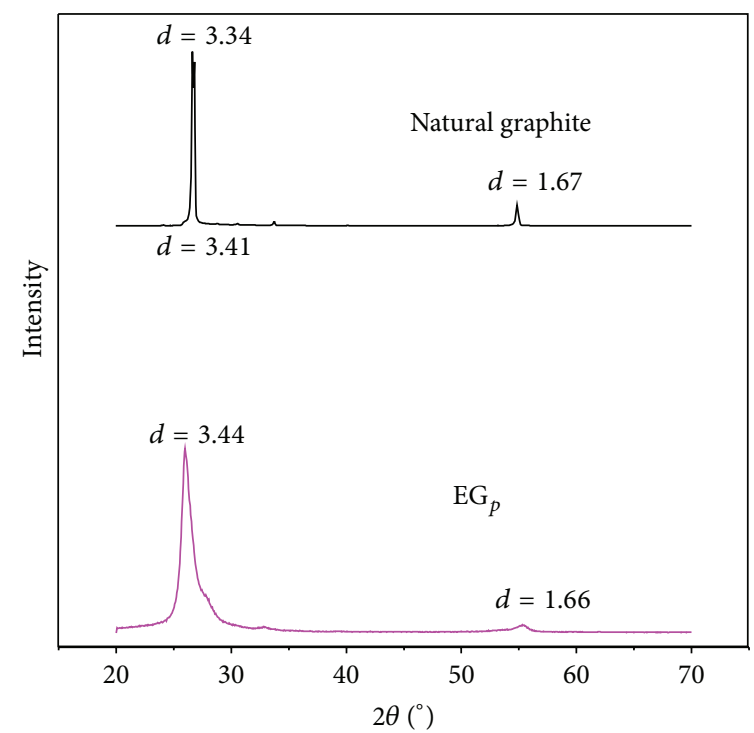

FIGURE 5: XRD of natural graphite and $\mathrm{EG}_{p}$.

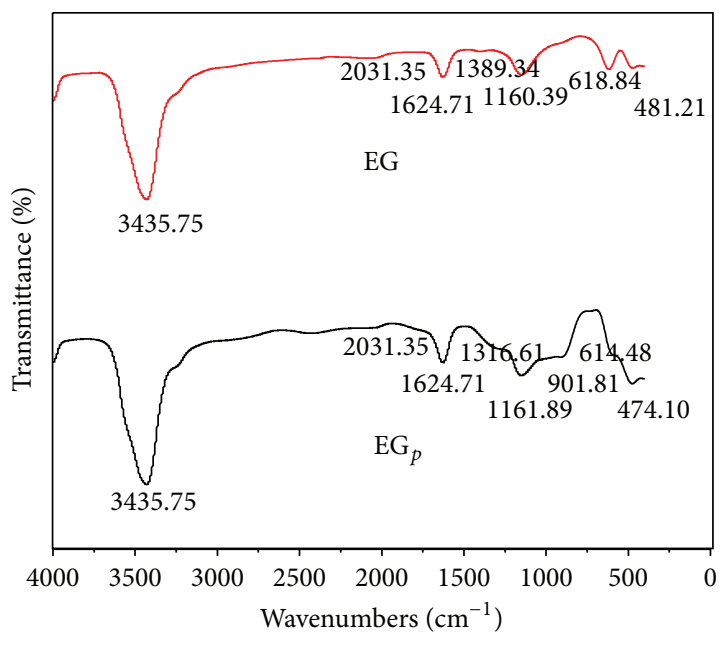

FIGURE 6: FTIR analysis of EG and $\mathrm{EG}_{p}$.

is the specific absorption peaks of $\mathrm{C}=\mathrm{C}$, originating from its conjugated structure. The absorption peaks of $\mathrm{S}=\mathrm{O}$ in $\mathrm{EG}$ are at $1160 \mathrm{~cm}^{-1}$, but there are wide superimposed peaks in the range of $1160-1110 \mathrm{~cm}^{-1}$ in the FTIR of $E G_{p}$, and it is because the absorption peaks of $\mathrm{S}=\mathrm{O}$ and $\mathrm{P}=\mathrm{O}$ both appear in the range of $1350-1100 \mathrm{~cm}^{-1}$ as reported [13]. Furthermore, the peaks at $1161 \mathrm{~cm}^{-1}$ and $901 \mathrm{~cm}^{-1}$ in $\mathrm{EG}_{p}$ all belong to SHMP specific absorption [14]. The results announce the intercalation of intercalator.

3.4. Detection of Flame Retardancy for LLDPE. Processing temperature of LLDPE is lower than $140^{\circ} \mathrm{C}$, so the prepared $\mathrm{EG}_{p}$ and $\mathrm{EG}$ can be used as retardant. The flame retarding composites were prepared as mentioned above, and their LOI of pure LLDPE, 70LLDPE/30EG ${ }_{p}$, and 70LLDPE/30EG (shown as wt\%) was detected according to the mentioned method. Results show that LOI of net LLDPE is only $17.5 \%$, 
and its combustion accompanies molten drop at the same time. Addition of $30 \%$ EG improves LOI to $24.6 \%$, and no molten drop occurs. However, the addition of the same amount of $\mathrm{EG}_{p}$ can improve LOI to $27.3 \%$, and no molten drop occurs too. Therefore, the intercalating STPP is more effectual in improving the flame retardancy.

\section{Conclusions}

According to the analysis of the experiment results, it is evident that the mass ratio of $\mathrm{C}: \mathrm{KMnO}_{4}: \mathrm{H}_{2} \mathrm{SO}_{4}$ (98\%) : SHMP has important influence on product dilatability, and when it is controlled as $1.0: 0.3: 4.5: 0.6, \mathrm{H}_{2} \mathrm{SO}_{4}$ was diluted to $77 \mathrm{wt} \%$ before intercalation reaction, and intercalating reaction lasted for $40 \mathrm{~min}$ at $40^{\circ} \mathrm{C}$, the $\mathrm{EV}$ and $T_{0}$ of the prepared $\mathrm{EG}_{p}$ can reach $600 \mathrm{~mL} / \mathrm{g}$ and $151^{\circ} \mathrm{C}$, respectively. The intercalating reaction between graphite and $\mathrm{H}_{2} \mathrm{SO}_{4}$ and SHMP can be revealed by XRD and FTIR analysis of intercalation compounds. $\mathrm{EG}_{p}$ has more effective flame retardancy than the referenced EG.

\section{Conflict of Interests}

The authors declare that there is no conflict of interests regarding the publication of this paper.

\section{Acknowledgments}

This study is supported by Project (no. B2015201028) of Natural Science Foundation of Hebei Province. At the same time, the authors gratefully acknowledge the support of Seedling Project of College of Chemistry and Environmental Science, Hebei University.

\section{References}

[1] J. E. Fischer and T. E. Thompson, "Graphite intercalation compounds," Physics Today, vol. 31, no. 7, pp. 36-45, 2008.

[2] G. Q. Liu and M. Yan, "The preparation of expanded graphite using fine flaky graphite," New Carbon Materials, vol. 17, no. 2, pp. 13-18, 2002.

[3] T. S. Jin, Y. R. Ma, and Q. Li, "Kinetics on synthesis of propyl acetate catalyzed with expansible graphite," Chinese Journal of Inorganic Chemistry, vol. 13, pp. 231-233, 1997.

[4] M. Toyoda and M. Inagaki, "Heavy oil sorption using exfoliated graphite new application of exfoliated graphite to protect heavy oil pollution," Carbon, vol. 38, no. 2, pp. 199-210, 2000.

[5] F. Y. Kang, Y. P. Zheng, H. Zhao et al., "Sorption of heavy oils and biomedical liquids into exfoliated graphite-research in China," New Carbon Materials, vol. 18, no. 3, pp. 161-173, 2003.

[6] M. D. Vedenyapina and A. A. Vedenyapin, "Dynamic adsorption of drug preparations from aqueous solutions on thermally expanded graphite," Solid Fuel Chemistry, vol. 49, no. 1, pp. 4144, 2015.

[7] C. F. Kuan, K. C. Tsai, C. H. Chen, H. C. Kuan, T. Y. Liu, and C. L. Chiang, "Preparation of expandable graphite via $\mathrm{H}_{2} \mathrm{O}_{2}$-hydrothermal process and its effect on properties of highdensity polyethylene composites," Polymer Composites, vol. 33, no. 6, pp. 872-880, 2012.
[8] Z. D. Sun, Y. H. Ma, Y. Xu et al., "Effect of the particle size of expandable graphite on the thermal stability, flammability, and mechanical properties of high-density polyethylene/ethylene vinyl-acetate/expandable graphite composites," Polymer Engineering \& Science, vol. 54, no. 5, pp. 1162-1169, 2014.

[9] Y. B. Lu, Y. J. Zhang, and W. J. Xu, "Flame retardancy and mechanical properties of ethylene-vinyl acetate rubber with expandable graphite/ammonium polyphosphate/dipentaerythritol system," Journal of Macromolecular Science, Part B: Physics, vol. 50, no. 10, pp. 1864-1872, 2011.

[10] L. Wang, K. M. Song, S. H. Zhang, Q. Li, Y. P. Li, and M. Liu, "Study on preparation of the high expansion volume and low temperature expandable graphite," Bulletin of the Chinese Ceramic Society, vol. 28, no. 4, pp. 844-849, 2009.

[11] X. Y. Pang, Y. Tian, M. W. Duan, and M. Zhai, "Preparation of low initial expansion temperature expandable graphite and its flame retardancy for LLDPE," Central European Journal of Chemistry, vol. 11, no. 6, pp. 953-959, 2013.

[12] L. Wang, K. M. Song, M. Y. Zhang, and T. Feng, "Preparation of expandable graphite of high initiation expansion temperature using close agent," Non-Metallic Mines, vol. 31, no. 1, pp. 19-21, 2008.

[13] H. Li, J. W. Zhang, and X. H. Wang, "Identification of unknown components by Fourier infrared spectrometer," Chinese Journal of Frontier Health and Quarantine, vol. 17, no. 5, pp. 98-100, 1994.

[14] G. T. Ling, Handbook of Food Additives, vol. 848, 3rd edition, 2003. 

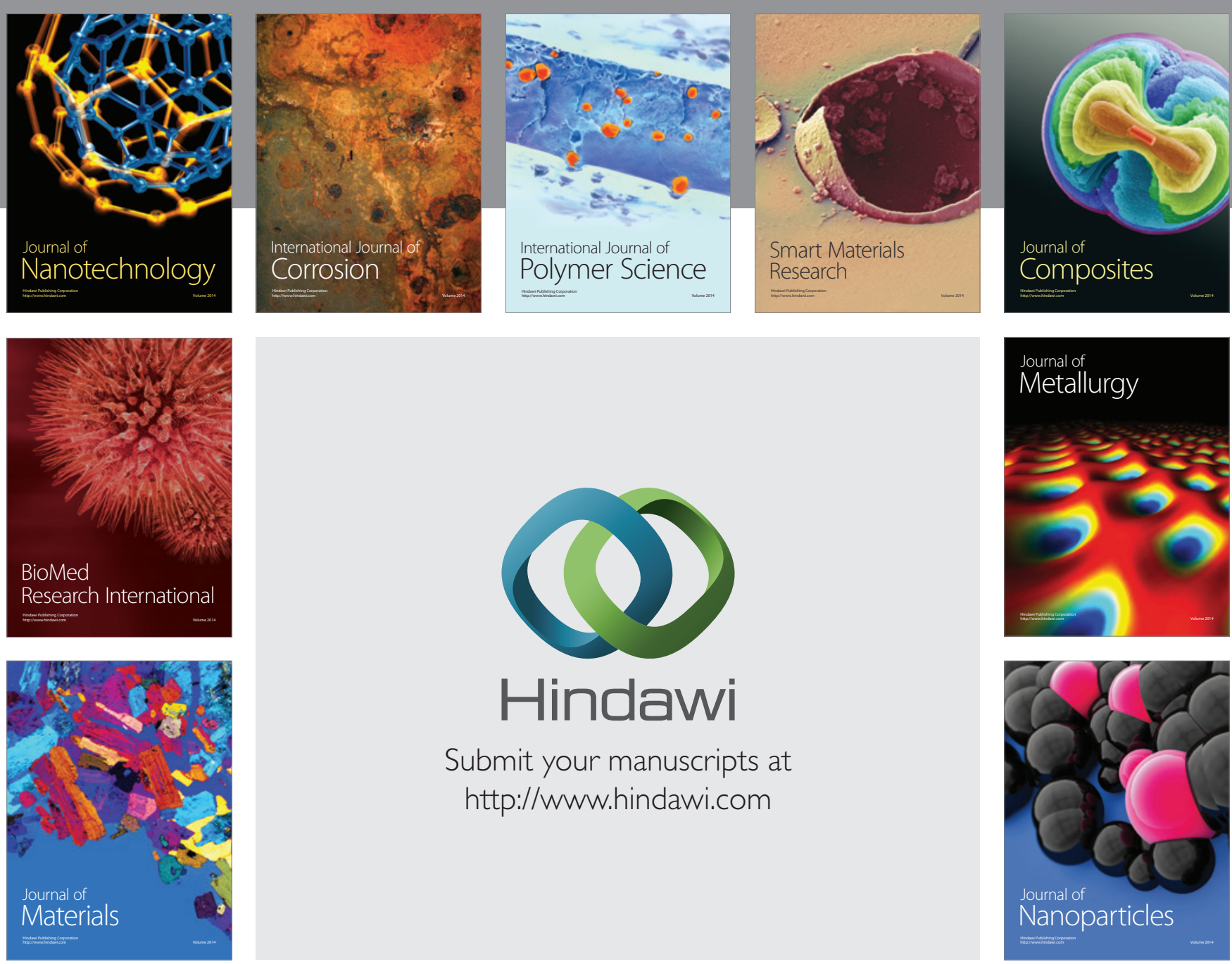

Submit your manuscripts at http://www.hindawi.com
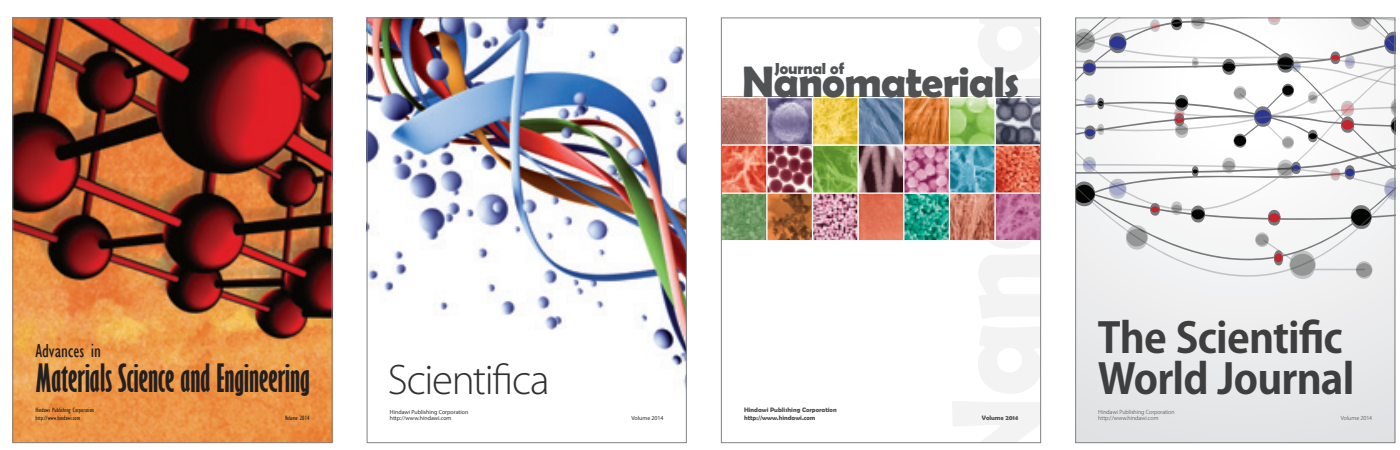

\section{The Scientific World Journal}
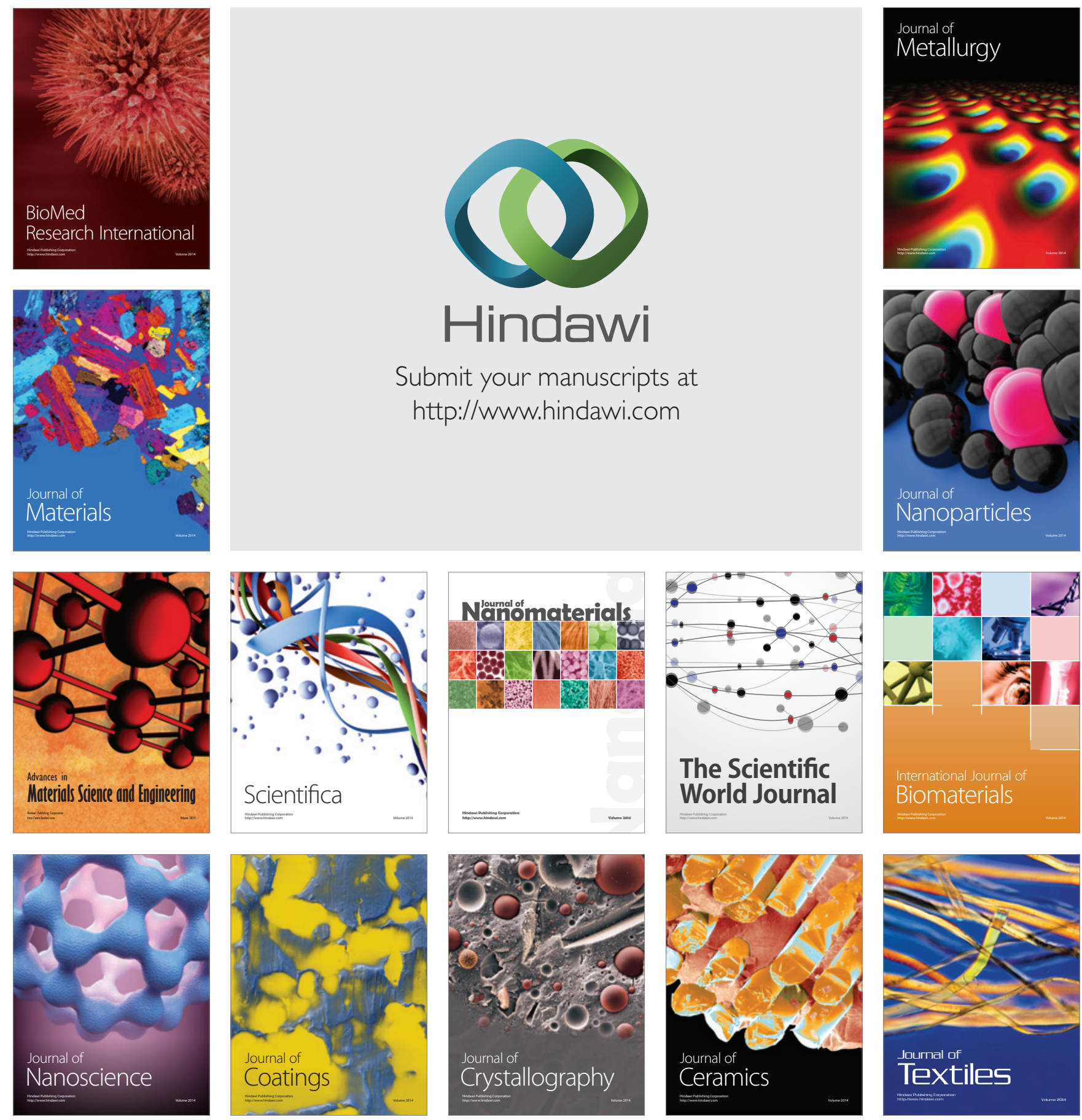